\title{
POTENSI KEHANCURAN TANAH LANAU KELEMPUNGAN YANG DIPADATKAN DI LABORATORIUM DENGAN KANDUNGAN LEMPUNG YANG BERBEDA
}

\author{
Aniek Prihatiningsih ${ }^{1}$, Alfred Jonathan Susilo ${ }^{2}$, Gregorius Sandjaja Sentosa ${ }^{3}$ \\ ${ }^{1}$ Program Studi Teknik Sipil, Universitas Tarumanagara, Jakarta \\ Email: aniekp@ft.untar.ac.id \\ ${ }^{2}$ Program Studi Teknik Sipil, Universitas Tarumanagara, Jakarta \\ Email: alfred@ft.untar.ac.id \\ ${ }^{3}$ Program Studi Teknik Sipil, Universitas Tarumanagara, Jakarta \\ Email: gregoriuss@ft.untar.ac.id
}

\begin{abstract}
ABSTRAK
Kehancuran tanah mendadak (Collapsible soil) adalah tanah yang mengalami penyusutan volume secara ekstrim dan mendadak. Peremeter yang menggambarkan kehancuran mendadak dilihat dari nilai $\mathrm{Cp}$ (potensi collapse), semakin meningkat nilai $\mathrm{Cp}$ maka tingkat kesulitannya akan semakin besar. Pemadatan tanah yang dilakukan dalam kondisi lebih kering daripada kadar air optimum cenderung dapat terjadi kehancuran mendadak (collapsible soil). Tanah yang mengandung lempung yang lebih banyak telah diuji pemadatan di laboratorium pada kondisi lebih kering daripada kadar air optimum (95\% lebih kering dari kadar air optimum) untuk mengetahui potensi kehancuran mendadak. Tanah yang dipadatkan tersebut diuji pada alat konsolidasi dengan kondisi awal tanpa direndam pada tegangan prakonsolidasi, kemudian contoh tanah direndam 24 jam dengan kondisi diberi tegangan tetap pada tegangan prakonsolidasi. Tanah yang mengandung lempung lebih banyak akan memperlihatkan potensi kehancuran mendadak yang lebih rendah dibandingkan tanah yang mengandung lempung lebih sedikit. Tujuan dari penelitian ini adalah untuk mengetahui potensi kehancuran mendadak pada tanah dengan kandungan lempung yang berbeda. Contoh tanah yang di teliti diambil dari Sidrap-Sulawesi Selatan dan Citra-Banten. Penelitian dilakukan di laboratorium makanika tanah universitas Tarumanagara. Hasil pengujian karakteristik tanah menunjukkan tanah Sidrap-Sulawesi dan tanah Citra-Banten dengan menggunakan AASHTO (American Association of State Highway and Transportation Officials) keduanya tergolong dalam jenis yang sama yaitu A-7-5. Dari hasil pengujian kandungan lempung untuk tanah Sidrap-Sulawesi sebesar $17.42 \%$ dan Citra-Banten sebesar 10.53\%. Tanah Citra-Banten memiliki kandungan lempung lebih sedikit memperlihatkan potensi kehancuran mendadak yang lebih rendah.
\end{abstract}

Kata Kunci: Pemadatan tanah; kehancuran mendadak tanah (collapsible soil); kadar air optimum; uji kehancuran tanah; uji konsolidasi

\section{ABSTRACT}

Sudden destruction of land (Collapsible soil) is land that experiences extreme and sudden volume depreciation. Peremeter which illustrates the sudden collapse seen from the value of $C p$ (potential collapse), the more the value of Cp, the greater the difficulty level. Soil compaction carried out in conditions drier than the optimum moisture content tends to occur sudden destruction (collapsible soil). Soil containing more clay has been tested compaction in a laboratory at drier conditions than the optimum moisture content ( $95 \%$ drier than the optimum water content) to determine the potential for sudden destruction. The compacted soil is tested on a consolidation tool with initial conditions without being immersed at the preconsolidation stress, then the soil sample is soaked for 24 hours with a constant stressed condition at the preconsolidation voltage. Soils containing more clay will show a lower potential for sudden destruction than soils containing less clay. The purpose of this study is to determine the potential for sudden destruction on soils with different clay contents. Examples of examined soil were taken from Sidrap-South Sulawesi and Citra-Banten. The study was conducted at the Tarumanagara University soil food laboratory. The results of the soil characteristics test show that Sidrap-Sulawesi and Citra-Banten soils using AASHTO (American Association of State Highway and Transportation Officials) are both classified in the same type, A-7-5. From the test results the clay content for SidrapSulawesi was $17.42 \%$ and Citra-Banten was $10.53 \%$. Citra-Banten soil has less clay content showing a lower potential for sudden destruction.

Keywords: soil compaction; sudden destruction of soil (collapsible soil); optimum moisture content; soil destruction test; consolidation test 


\section{PENDAHULUAN}

Kondisi topografi wilayah Indonesia dominan berbentuk perbukitan sehingga memiliki potensi kelongsoran yang dipengaruhi beberapa faktor seperti, kecuraman suatu lereng, faktor muka air tanah dan faktor beban luar. Hal tersebut dapat mengakibatkan lereng-lereng mengalami longsor atau mengalami kegagalan yang dapat mengakibatkan korban jiwa dan kehilangan harta benda. Collapsible soil merupakan jenis tanah yang rentan mengalami penyusutan volume secara tibatiba dan ekstrim. Collapsible soil biasanya terjadi pada tanah loose, cemented soil, tanah dengan kepadatan kering rendah, dan sensitivitas tinggi.

Sifat jenis tanah akan mengembang pada saat ditambahkan air, namun apabila kadar air meningkat melebihi kondisi optimum sehingga kejenuhan melebihi 100\%, tanah akan runtuh akibat hancurnya ikatan antar butiran tanah (tanah berperilaku seperti lumpur). Tanah jenis ini biasanya merupakan tanah endapan, tanah yang sudah mengalami perpindahan dan mengalami siklus pengaruh cuaca berkali-kali. Faktor yang memicu keruntuhan tanah biasanya disebabkan oleh beban yang bertambah, tanah mengalami pembasahan, atau kombinasi dari keduanya. Pada saat beban bertambah, maka tegangan yang diterima tanah meningkat, dan ketika tanah mengalami pembasahan akan meningkatkan kejenuhan tanah dari tidak jenuh atau jenuh sebagian menjadi jenuh.

Untuk mengetahui potensi kehancuran (collapsible soil) perlu dianalisis kandungan jenis tanah atau komposisi ukuran butir. Penelitian ini mengambil contoh tanah dari daerah Sidrap-Sulawesi Selatan dan Citra-Tangerang, Provinsi Banten untuk mengetahui potensi kehancurannya dengan memperhatikan komposisi ukuran butir atau kandungan jenis tanahnya.

Penelitian dilakukan dengan memadatkan tanah di laboratorium dengan alat kompaksi sampai mencapai kondisi 95\% lebih kering daripada kadar air optimum. Kemudian tanah dicetak pada alat konsolidasi dan diberikan beban pada tekanan prakonsolidasi. Setelah itu dilakukan pembasahan sampai jenuh dan kemudian diamati proses kehancurannya dan diukur potensi kehancurannya.

\section{METODE PENELITIAN}

Penelitian dimulai dengan menguji karakteristik tanah dari kedua lokasi. Hasil uji karakteristik tanah dapat dilihat pada Tabel 1. di bawah ini. 
Tabel 1. Karakteristik Tanah Sidrap-Sulawesi Selatan dan Citra-Banten

\begin{tabular}{|c|c|c|}
\hline \multirow[t]{2}{*}{ Lokasi pengambilan sampel } & \multicolumn{2}{|c|}{ Benda uji } \\
\hline & Sidrap & Citra \\
\hline \multicolumn{3}{|l|}{ SPECIFIC GRAVITY } \\
\hline Gs & 2.62 & 2.70 \\
\hline \multicolumn{3}{|l|}{ ATTERBERG (batas plastis) } \\
\hline Batas Cair, $\mathrm{w}_{\mathrm{L}}(\%)$ & 57.81 & 78.80 \\
\hline Batas Plastis, $\mathrm{w}_{\mathrm{P}}(\%)$ & 33.27 & 43.40 \\
\hline Indeks Plastisitas, $\mathrm{I}_{\mathrm{p}}(\%)$ & 24.54 & 31,78 \\
\hline \multicolumn{3}{|l|}{ GRAIN SIZE (ukuran butir) } \\
\hline Gravel $(\%)$ & 0 & 1,26 \\
\hline Pasir $(\%)$ & 30.28 & 5.14 \\
\hline Lanau $(\%)$ & 52.30 & 84.33 \\
\hline Lempung $(\%)$ & 17.42 & 10.53 \\
\hline Klasifikasi Tanah (AASHTO) & A-7-5 & A-7-5 \\
\hline Klasifikasi Tanah (USCS) & ML & MH \\
\hline \multicolumn{3}{|l|}{ PARAMETER PEMADATAN STANDAR } \\
\hline Kadar air optimum (OMC), $\mathrm{w}_{\text {opt }} .(\%)$ & 22.00 & 40.24 \\
\hline Berat isi kering maksimum, $\gamma_{\mathrm{dmaks}}\left(\mathrm{kN} / \mathrm{m}^{3}\right)$ & 13.77 & 12.08 \\
\hline $\mathrm{OMC}-5 \%\left(95 \% \mathrm{~b}_{\mathrm{b}}, \mathrm{w}_{\mathrm{opt}}(\%)\right.$ & 13.80 & 32.00 \\
\hline$\gamma_{\mathrm{d} 95 \% \mathrm{~b}}\left(\mathrm{kN} / \mathrm{m}^{3}\right)$ & 13.08 & 11.47 \\
\hline
\end{tabular}

Hasil pemadatan tanah yang menghasikan kadar air optimum dapat dilihat pada Tabel 1. dan kondisi 95\% lebih kering daripada kadar air optimum pada sisi kering dapat dilihat juga pada tabel tersebut. Untuk melakukan uji collapsible soil tanah dibentuk pada kondisi $95 \%$ lebih kering daripada kadar air optimum dan contoh tanah dicetak pada ring alat konsolidasi dan kemudian dilakukan proses pengujian collapsible soil menggunakan konsolidometer.

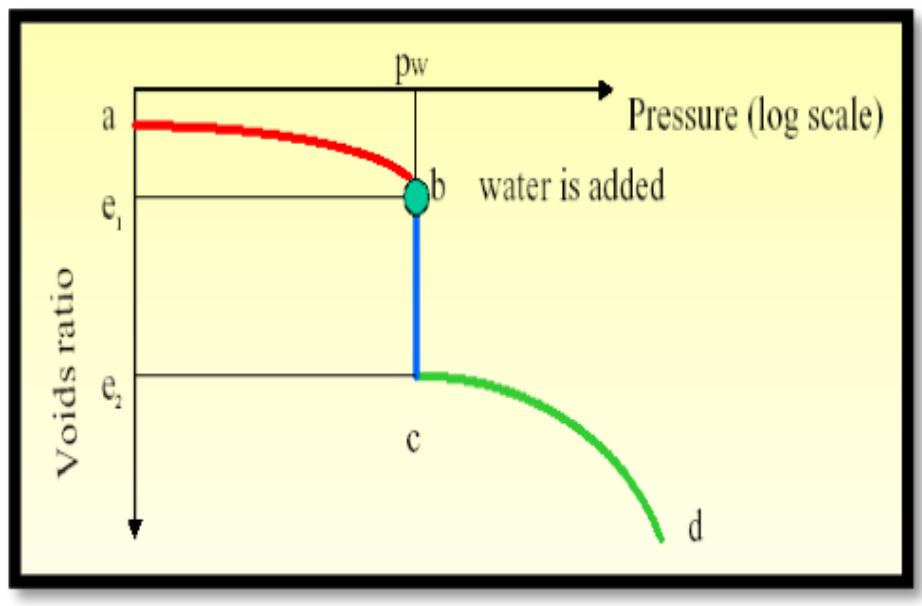

Gambar 1. Tipikal hasil uji collapsible soil

Keterangan gambar:

$\mathrm{ab}=$ ditentukan dari tes konsolidasi pada contoh tanah saat kadar air awal.

$\mathrm{e}_{1}=$ angka pori sebelum penjenuhan.

$\mathrm{e}_{2}=$ angka pori setelah penjenuhan.

$\mathrm{cd}=$ kurva yang terjadi dari penambahan beban setelah penjenuhan. 
Tipikal hasil uji collapsible soil tergambar seperti Gambar 1. Dari hasil uji collapsible soil dapat dianalisis potensi kehancurannya dengan menggunakan kriteria yang diusulkan Jennings dan Knight, 1975 menyarankan beberapa nilai untuk potensi keruntuhan seperti yang ditunjukkan pada Tabel 2. Nilainilai ini hanya kualitatif untuk menunjukkan keparahan masalah.

Tabel 2. Nilai potensi collapsible soil

Sumber: Jennings dan Knight, 1975

\begin{tabular}{cl}
\hline Cp [\%] & Keparahan masalah \\
\hline $0-1$ & Tidak ada masalah \\
\hline $1-5$ & Tingkat kesulitan sedang \\
\hline $3-10$ & Tingkat kesulitan cukup \\
\hline $10-20$ & Tingkat kesulitan parah \\
\hline$>20$ & Tingkat kesulitan sangat parah \\
\hline
\end{tabular}

Potensi collapse $\mathrm{Cp}$ dinyatakan sebagai berikut:

$$
C p=\frac{\Delta e_{c}}{1+e_{0}}=\frac{\Delta H_{c}}{H_{0}}
$$

Dimana: $\Delta e_{c}=$ perubahan angka pori setelah penjenuhan

$\mathrm{e}_{0} \quad=$ angka pori mula-mula

$\Delta H_{c}=$ perbedaan tinggi setelah penjenuhan

$\mathrm{H}_{\mathrm{o}}=$ Tinggi mula-mula

US Department of Transportation, 2006 menyarankan juga beberapa nilai untuk potensi keruntuhan seperti yang ditunjukkan pada Tabel 3.

Tabel 3. Nilai potensi keruntuhan tanah

Sumber: US Department of Transportation, 2006

\begin{tabular}{cl}
\hline $\mathrm{Cp}[\%]$ & Keparahan masalah \\
\hline 0 & Tidak ada masalah \\
\hline $0.1-2$ & Tingkat kesulitan sedikit \\
\hline $2.1-6$ & Tingkat kesulitan sedang \\
\hline $6.1-10$ & Tingkat kesulitan cukup parah \\
\hline$>10$ & Tingkat kesulitan parah \\
\hline
\end{tabular}

Moghadam et al., 2006 menyajikan grafik yang menunjukkan hubungan antara berat kering dan persentase lebih halus dari $0-0.75 \mathrm{~mm}$ (ayakan no. 200) untuk mengevaluasi potensi runtuhnya berbagai jenis tanah, seperti yang ditunjukkan pada Gambar 2.

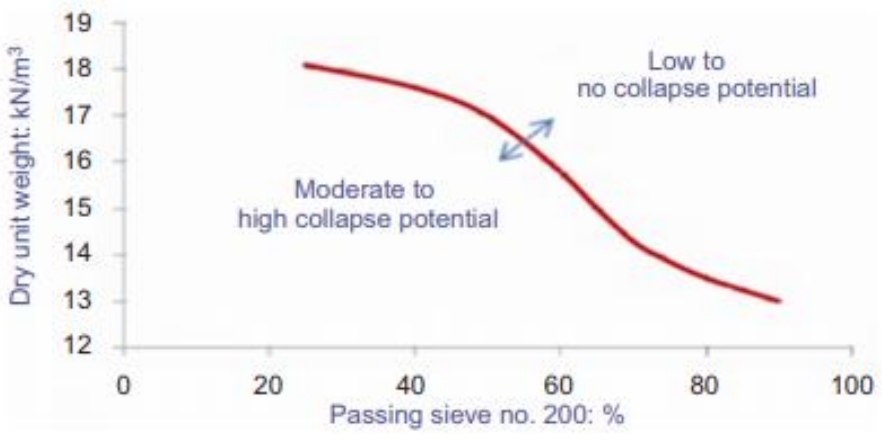

Gambar 2. Potensi keruntuhan tanah berdasarkan ukuran butir dan kepadatannya (Moghadam et al., 2006) 
Dari hasil uji laboratorium dapat ditentukan potensi terjadi kehancuran tanah Sidrap dan Citra. Penelitian ini akan memprediksi potensi kehancuran tanah lanau kelempungan yang dipadatkan di laboratorium dengan kandungan lempung yang berbeda. Dasar perkiraan potensi kehancuran dengan mengikuti kriteria yang sudah diusulkan seperti di atas.

\section{HASIL DAN PEMBAHASAN}

Pelaksanaan penelitian ini dilakukan di laboratorium Mekanika Tanah Universitas Tarumanagara. Hasil pengujian karakteristik tanah dapat dilihat pada Tabel 1. Jenis tanah yang diuji menghasilan klasifikasi tanah Sidrap dan Citra menurut AASHTO tergolong pada A-7-5, tetapi menurut USCS tanah Sidrap tergolong ML dan Citra tergolong MH.

Dari uji Atterberg (batas plastis) untuk tanah Sidrap diperoleh nilai batas cair $\left(\mathrm{W}_{\mathrm{L}}\right)$, batas plastis $\left(\mathrm{W}_{\mathrm{P}}\right)$, dan indeks plastisitas $\left(\mathrm{I}_{\mathrm{P}}\right.$ ) seluruhnya lebih kecil dibandingkan tanah Citra. Untuk uji ukuran butir (Grain Size) kandungan pasir tanah Sidrap 30.28\%, Citra 5.14\%, kandungan lanau 52.30\% untuk Sidrap dan 84.33\% untuk Citra, serta lempung $17.42 \%$ dan Citra 10.53\%. Terlihat bahwa kandungan lempung Citra lebih sedikit dibandingkan Sidrap. Bila dilihat dari uji pemadatan terlihat kadar air optimum Citra (40.24\%) lebih tinggi dibandingkan Sidrap (22.00\%). Sedangkan kepadatan isi kering maksimum tanahnya tidak selisih jauh $13.77 \%$ Sidrap dan $12.08 \%$ Citra.

Pada uji menggunakan alat konsolidometer untuk menentukan nilai, tegangan pra-konsolidasi, $\mathrm{P}_{\mathrm{c}}$ pada tanah dipadatkan dengan alat kompaksi sampai mencapai kondisi 95\% lebih kering daripada kadar air optimum didapat hasil seperti pada Tabel 4.

Tabel 4. Nilai $\mathrm{P}_{\mathrm{c}}$ yang digunakan untuk Collapsible Soil pada kepadatan tanah $95 \%$ lebih kering daripada kadar air optimum

\begin{tabular}{lcc}
\hline Lokasi pengambilan sampel & \multicolumn{2}{c}{ Nilai $\mathrm{P}_{\mathrm{c}}$} \\
\cline { 2 - 3 } & $\left(\mathrm{kg} / \mathrm{cm}^{2}\right)$ & $\left(\mathrm{kN} / \mathrm{m}^{2}\right)$ \\
\hline Sidrap-Sulawesi Selatan & 1 & 98.0665 \\
\hline Citra-Tangerang Banten & 1.045 & 102.4796 \\
\hline
\end{tabular}

Pengujian untuk mengetahui potensi collapsible soil, dilakukan dengan menggunakan alat kosolidometer dengan memberikan tekanan sampai mencapai tekanan pra-konsolidasi untuk masing-masing daerah. Setelah itu dilakukan pembasahan sampai jenuh selama 24 jam dan diamati proses kehancurannya dan diukur potensi kehancurannya.

Gambar 3. Memperlihatkan perbedaan angka pori sebelum dan sesudah penjenuhan pada kondisi kepadatan 95\% lebih kering daripada kadar air optimum untuk tanah Sidrap. 


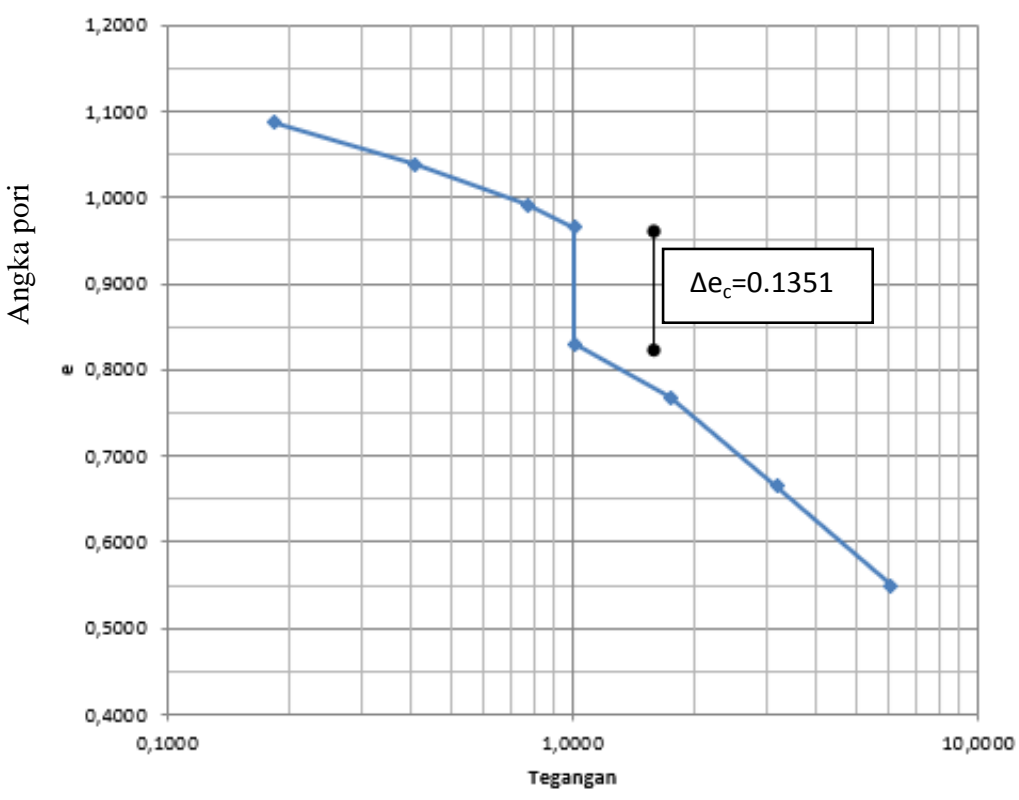

Gambar 3. Potensi keruntuhan tanah berdasarkan ukuran butir dan kepadatannya tanah Sidrap.

Pada Tabel 5. Memperlihat perbedaan penurunan angka pori $\left(\Delta \mathrm{e}_{\mathrm{c}}\right)$ pada saat tekanan mencapai tekanan prakonsolidasi dan dilakukan penjenuhan sebelum dilakukan pembebanan kembali.

Tabel 5. Perbedaan Angka Pori Sebelum dan Sesudah Penjenuhan pada Kepadatan Tanah 95\% lebih kering daripada kadar air optimum

\begin{tabular}{lcc}
\hline Lokasi pengambilan sampel & \multicolumn{2}{c}{$\Delta \mathrm{e}_{\mathrm{c}}$} \\
\cline { 2 - 3 } & Sampel 1 & Sampel 2 \\
\hline Sidrap-Sulawesi Selatan & 0.1351 & 0.1307 \\
\hline Citra-Tangerang Banten & 0.041 & 0.034 \\
\hline
\end{tabular}

Tabel 6. Menunjukkan nilai angka pori awal, selisih angka pori sebelum dan sesudah dijenuhkan, dan nilai potensi keruntuhan, $\mathrm{Cp}$.

Tabel 6. Nilai angka pori awal, selisih angka pori dan potensi keruntuhan pada Kepadatan Kering 95\% lebih kering daripada kadar air optimum

\begin{tabular}{cccc}
\hline $\begin{array}{c}\text { Lokasi Pengambilan } \\
\text { Sampel }\end{array}$ & $\begin{array}{c}\text { Angka Pori } \\
\text { Awal } \mathrm{e}_{0}\end{array}$ & $\begin{array}{c}\text { Selisih Angka } \\
\text { Pori } \Delta \mathrm{e}_{\mathrm{c}}\end{array}$ & $\begin{array}{c}\text { Nilai potensi } \\
\text { keruntuhan Cp [\%] }\end{array}$ \\
\hline $\begin{array}{c}\text { Sidrap-Sulawesi } \\
\text { Selatan }\end{array}$ & 0.965 & 0.1351 & 6.88 \\
\cline { 3 - 4 } $\begin{array}{c}\text { Citra-Tangerang } \\
\text { Banten }\end{array}$ & \multirow{2}{*}{1.309} & 0.1307 & 6.65 \\
\cline { 3 - 4 } & & 0.041 & 1.78 \\
\hline
\end{tabular}

Dari hasil pengujian dapat digambarkan dalam bentuk grafik keruntuhan terhadap kepadatan, kandungan lempung, kandungan butir halus dan batas cair sebagai gambar berikut: 


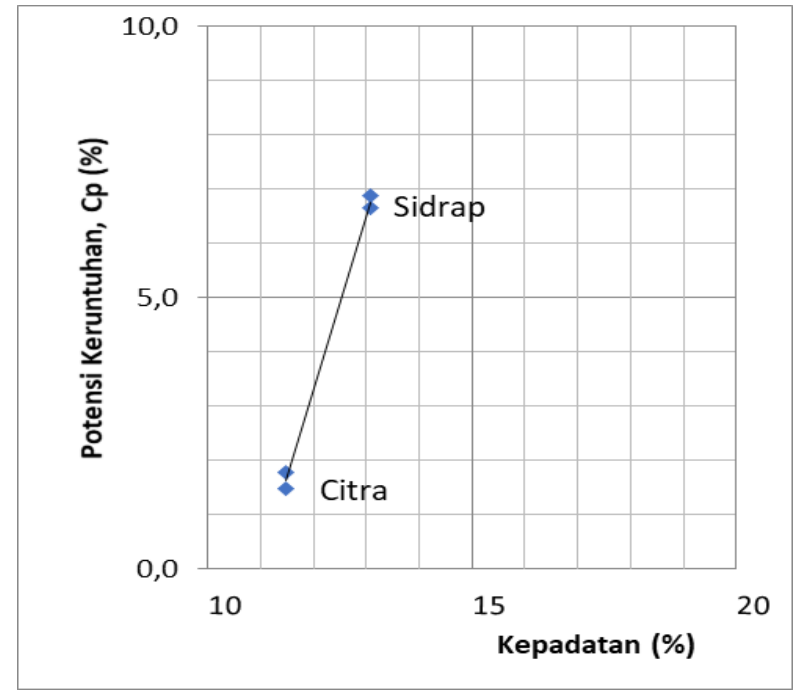

Gambar 4. Potensi keruntuhan terhadap kepadatan

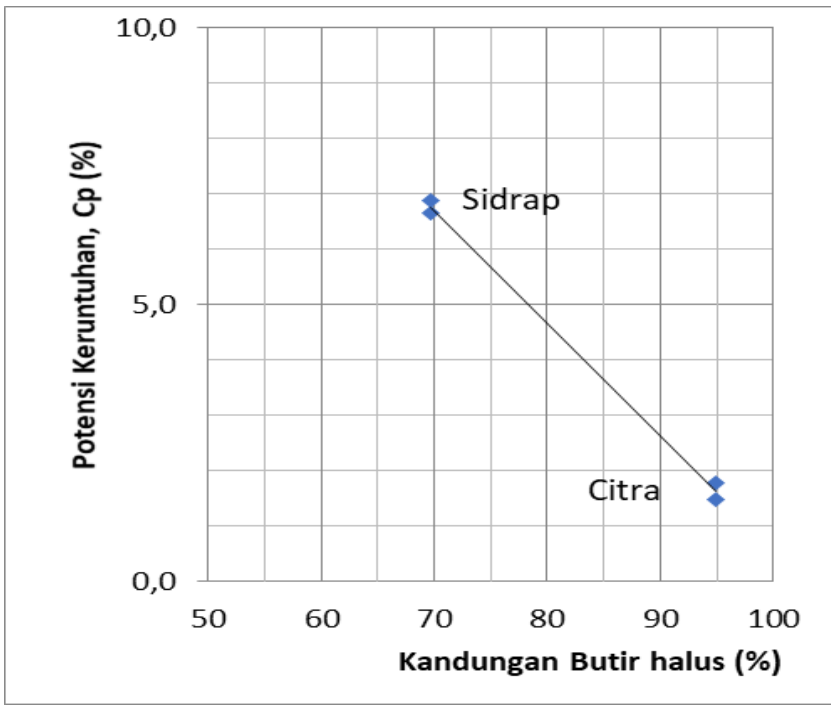

Gambar 6. Potensi keruntuhan terhadap kandungan butiran halus

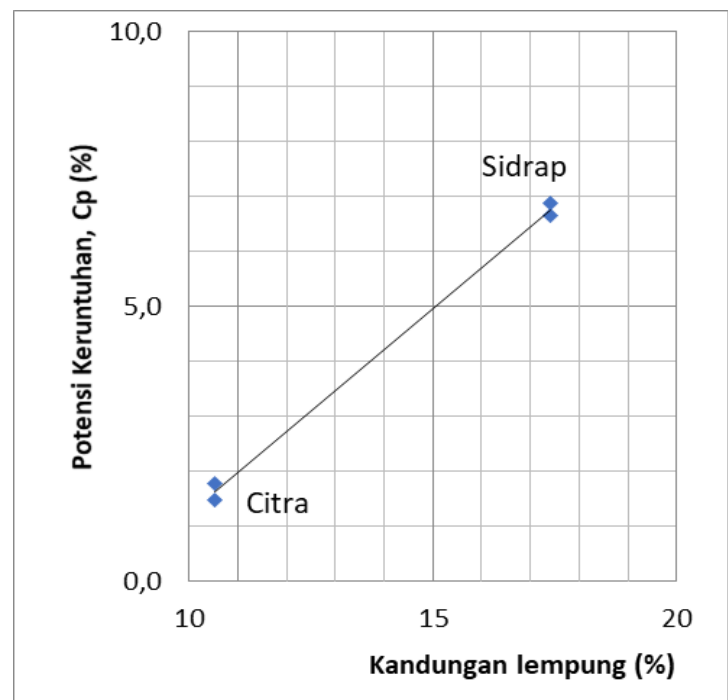

Gambar 5. Potensi keruntuhan terhadap kandungan lempung

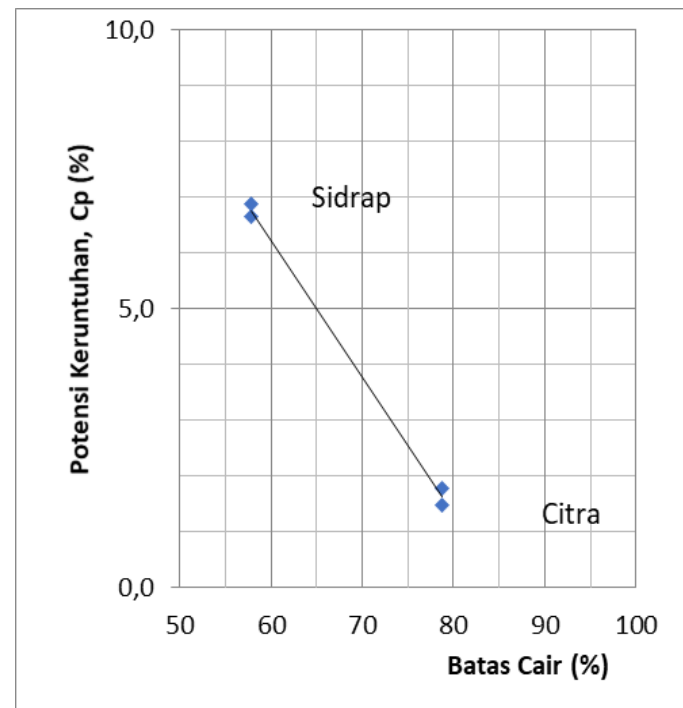

Gambar 7. Potensi keruntuhan terhadap batas cair

Dari pengujian tanah Sidrap dan Citra terlihat pada Gambar 4. kepadatan tanah semakin tinggi, tanah cenderung collapse. Pada Gambar 5. kandungan lempung semakin banyak, maka tanah cenderung memiliki nlai potensi collapse lebih tinggi, yang artinya mudah terjadi collapse. Gambar 6. kandungan butiran halus semakin banyak kecenderungan tanah mengalami collapse semakin rendah dan pada Gambar 7. kandungan batas cair semakin besar, maka potensi keruntuhan semakin kecil. 


\section{KESIMPULAN DAN SARAN}

\section{Kesimpulan}

Kesimpulan pada penelitian ini hanya untuk tanah dari daerah Sidrap-Sulawesi Selatan dan Citra-Tangerang Banten.

a. Berdasarkan kepadatan kering dan kandungan lempung, tanah Sidrap cenderung meng-alami collapse dengan tingkat kesulitan yang cukup parah. Untuk tanah Citra dengan tingkat kesulitan sedikit sampai sedang.

b. Berdasarkan kandungan butir halus dan batas cair, tanah Sidrap cenderung mengalami collapse dengan tingkat kesulitan yang cukup parah. Untuk tanah Citra dengan tingkat kesulitan sedikit sampai sedang.

\section{Saran}

Untuk mendapatkan nilai yang lebih akurat perlu dilakukan pengujian dengan jumlah lokasi sampel lebih banyak sehingga dapat disimpulkan pengaruh butiran halus terhadap kecenderungan runtuh.

\section{UCAPAN TERIMA KASIH}

Penelitian ini dapat terselenggara karena dukungan dana dari Direktorat Penelitian dan Pengabdian Masyarakat Universitas Tarumanagara tahun 2017.

\section{REFERENSI}

American Association of State Highway and Transportation Organization (AASHTO), (2011), Standard Specification for Transportation Materials and Methods of Sampling and Testing, Washington D.C.

American Society for Testing and Materials (ASTM) (2009), Soil and Rock (I), Vol. 04.08, Pennsylvania, USA.

Jennings JE and Knight K (1975) A guide to construction on or with materials exhibiting additional settlement due to collapse of grain structure. Proceedings of the 6th Regional Conference for Africa on Soil Mechanics and Foundation Engineering, Durban, South Africa. Proc. $6^{\text {th }}$ African Conf. Soil Mech. Found. Engg, Durban, 99- 105.

Moghadam MJ, Moghadam HA and Rahmannejad R (2006) Urban tunneling in collapsible soil (case study: the Kerman Metro). Proceedings of the National Conference on Retrofitting of Iran, Tabriz, Iran.

Sentosa, G. S., Aniek P., Djunaedi K. (2015), Uji Desak Bebas terhadap Material Tanah untuk Mengevaluasi Batas-batas Kinerja untuk Struktur Perkerasan Jalan yang Memiliki Ketahanan 50 Tahun, Universitas Tarumanagara, Jakarta.

SNI (Standar Nasional Indonesia) (2016), Cara uji pengukuran potensi keruntuhan tanah di laboratorium, SNI 8072:2016

US Department of Transportation (2006) Soil and Foundation, Reference Manual. US Department of Transportation, Washington, DC, USA, vol. I, publication no. FHWA NHI06-088, section 5-21. 